\title{
Os manuais de medicina popular do Império e as doenças dos escravos: o exemplo do "Chernoviz"*
}

Maria Regina Cotrim Guimarães

O presente trabalho apresenta os conhecidos manuais de medicina popular da autoria do polonês Pedro Luiz Napoleão Chernoviz (1812-1881) no contexto médico do Brasil imperial, tanto como elementos de divulgação da ciência médica acadêmica, quanto como elementos da medicina popular propriamente dita (nesse caso, devido à sua larga utilização por leigos). O caráter acadêmico, pedagógico, civilizador e higienista destes manuais do Império capacitava pessoas do interior do país, distantes dos médicos, aos primeiros socorros e à formulação de diversos remédios.

Palavras chave: Chernoviz, medicina popular, Brasil-Império, manuais médicos

* Este artigo corresponde a trabalho apresentado no Simpósio Escravidão, tráfico, raça e pathos: novas perspectivas da história das moléstias dos negros cativos no Brasil, durante o III Congresso Internacional de Psicopatologia Fundamental e IX Congresso Brasileiro de Psicopatologia Fundamental, ocorrido em Niterói (RJ), em setembro de 2008. 
Febre amarela. Esta moléstia é particular a certos países quentes; reina nas Antilhas, Nova Orleans, e em algumas regiões intertropicais. É caracterizada pela cor amarela da pele e pelos vômitos pretos (...), não era conhecida no Rio de Janeiro até 30 de dezembro de 1849, (...) havendo aparecido na Bahia dois meses antes. É verdade que tinha grassado em Pernambuco em 1684, mas esta data antiga estava riscada da memória (...). Nos pretos a moléstia se apresentou geralmente menos grave, e na minha clínica não vi nenhum deles morrer de febre amarela, como também não vi a moléstia chegar até o vômito preto nessa raça. A moléstia acometia sobretudo os estrangeiros não aclimados (...). (Chernoviz, 1862)

Bichos dos pés. (...) Este bicho, denominado pelos naturalistas pulex penetrans, é provido de seis pés, de cor preta e parece-se com uma pulga mui pequena (...). Os negros, que andam descalços, são freqüentemente incomodados por suas mordeduras: ele atravessa entretanto os vestidos, insinua-se em toda parte e nunca abandona voluntariamente a presa que tem agarrado. As crianças, as moças e as pessoas de pele fina são mais freqüentemente feridos ${ }^{1}$ por ele. (...). (Chernoviz, 1862)

Opilação. Moléstia dos países quentes caracterizada pela fraqueza geral (anemia), palidez e inchação da face, acompanhada muitas vezes de perversão do gosto (...). A falta de apetite alterna com a perversão do gosto, que consiste em desejar e comer substâncias não alimentárias e que causam mais ou menos asco no estado de saúde, tais como carvão, terra e outras até imundas. Este apetite pervertido pode faltar nos doentes da raça branca, mas é freqüente nos indivíduos de cor preta. É com verdadeiro furor que esses infelizes satisfazem seu gosto depravado. Para pôr obstáculo a esta paixão bizarra, é às vezes preciso recorrer aos meios coercitivos. Ao mesmo tempo que este gosto depravado aumenta, o apetite para coisas alimentárias vai diminuindo. A opilação é a conseqüência do enfraquecimento da economia devido à presença nos intestinos (...) de grande número de pequenos vermes chamados ancylostomos, que subtraem continuamente o sangue (...). (Chernoviz, 1890)

Os manuais de medicina popular da autoria do polonês Pedro Luiz Napoleão Chernoviz (1812-1881) são situados no contexto médico do Brasil imperial, tanto como elementos de divulgação da ciência médica acadêmica, quanto como ele-

\section{Grifos meus.}

Rev. Latinoam. Psicopat. Fund., São Paulo, v. 11, n. 4, p. 827-840, dezembro 2008 (Suplemento) 
mentos da medicina popular propriamente dita (nesse caso, devido à sua larga utilização por leigos). O caráter acadêmico, pedagógico, civilizador e higienista desses manuais do Império capacitava pessoas do interior do país, longe dos médicos, aos primeiros socorros e à formulação de diversos remédios. Num período em que a indústria dos livros foi incentivada, o tipo de manual escrito por Chernoviz alcançaria grande sucesso. Escreveu o Formulário ou guia médico (1 ${ }^{\text {a }}$ edição em 1841), dirigido à corporação médica, que vendeu, só no dia de lançamento, 300 exemplares, e que alcançou 19 edições; seu Dicionário de medicina popular ( $1^{\text {a }}$ edição em 1842), não menos conhecido, dirigido ao público leigo, foi editado seis vezes e a primeira edição vendeu 3.000 exemplares. Importante lembrarmos de que todas as edições foram atualizadas em função das mais recentes aquisições científicas.

O dr. Chernoviz não dirigiu sua obra ao tratamento dos escravos, mas conheceu muito bem a situação dos negros escravos e dos seus proprietários. Escreveu, numa das diversas cartas enviadas a uma pessoa querida, na Polônia, que o próprio capitão do navio que o trouxera ao Brasil foi-lhe dando a conhecer, durante a viagem, as técnicas grotescas de captura dos negros, nas costas da África, e como era burlada a lei que proibia o tráfico negreiro havia mais de dez anos. Denunciou, numa carta - muito didática - datada de sete meses após sua chegada (provavelmente julho de 1840), como "infame” o comércio clandestino de negros africanos - "ainda hoje são contrabandeados negros infelizes para o Brasil”, que "atados a uma só correia são levados para o porão”, onde diversos companheiros morrem, pelo calor, alimentação e espaço precários, o que "provoca, no fim, a revolta dos negros”, que atacam os marinheiros, enquanto “o capitão, que está sempre alerta e leva uma arma carregada, mata os primeiros corajosos que aparecem”, mas

... os restantes, assustados, recuam... Neste comércio de negros, não se presta atenção aos laços familiares; um irmão é separado do outro; o filho, do pai; a mãe, da criança. Os senhores casam seus escravos entre si, pois sabem por experiência que isso é a melhor maneira de torná-los bem comportados e dedicados à plantação... ele ajunta o casal, como igualmente pode separá-lo, vendendo a alguém um dos esposos... Se o escravo (...) provoca o descontentamento do senhor, por bebedeira, preguiça (...), o senhor castiga conforme a sua vontade (...) as leis que limitam a ira do senhor (...) não são observadas e a maldade do senhor não é reprimida... Nas cidades, todos os trabalhos pesados são executados pelos negros. Eu mesmo possuo um empregado negro que alugo de um dos habitantes locais. (Chernoviz, 1940)

Ao mesmo tempo, Chernoviz conseguia supor que, mesmo assim, "essa nova situação parece, para o negro recém-chegado, um paraíso em comparação 
à sua situação anterior na África”. Provavelmente esta carta foi escrita em dois tempos, um primeiro, logo na sua chegada, ainda chocado com as informações do capitão do navio, e o segundo, já mais estabilizado, convivendo com seu "empregado" de serviços pesados. A adaptação rápida às condições de sua nova terra foi uma das características desse médico. Entendeu que a vida na corte pressupunha etapas a serem cumpridas junto à corporação médica da cidade e junto ao imperador. Logo entraria para a Academia Imperial de Medicina e seus livros receberiam as bênçãos do imperador (Guimarães, 2003).

Os manuais de medicina popular do dr. Chernoviz, muito mais do que o contato regular com os médicos, foram um instrumento essencial de penetração de saberes e práticas sancionados pelas instituições médicas oficiais no quotidiano daquela população. O sucesso de sua obra ultrapassou os limites da corte do Rio de Janeiro, onde vivia, e, ao longo de múltiplas edições, foi muito difundida em todo o Brasil e traduzida para outros países.

Personagens famosos da literatura nacional foram freqüentadores do manual. Autores como Monteiro Lobato, Carlos Drummond de Andrade, Rubem Braga, Pedro Nava, Visconde de Taunay, Afrânio Peixoto, entre dezenas de outros não tão famosos, falaram, em suas obras, do Chernoviz, ${ }^{2}$ seja para afirmá-lo como um vade-mecum ou como puro charlatanismo. Machado de Assis não o nomeia, mas faz referência, em Dom Casmurro, ao personagem José Dias, indivíduo que veio a ser agregado da família de Bentinho, e que havia chegado à casa com uma caixa de botica e um manual. Ficcionais ou reais, os principais usuários do Chernoviz foram boticários, sinhôs e sinhás, que medicavam seus agregados e escravos, além de diversas lideranças políticas e religiosas, como o Padre Cícero, e de curiosos, para quem os manuais serviriam de salvo-conduto científico às suas medicinas junto à população. O Chernoviz, enquanto medicina de cabeceira, mostrou-se condizente com a estrutura social patriarcal, na medida em que seu conteúdo acadêmico se contaminaria de uma medicina doméstica, já familiar aos leitores (Guimarães, 2003).

Escritos por médicos vinculados às instituições acadêmicas imperiais, tanto Chernoviz como outros autores de manuais de medicina popular adaptaram à linguagem leiga os mais atualizados conhecimentos científicos, e constituíram, assim, um dos elos entre a medicina acadêmica e a população, em geral. A Academia Imperial de Medicina do Rio de Janeiro, criada em 1835, estava entranhada nas idéias iluministas, conseqüentes à formação européia dos médicos que aqui viviam desde antes da criação das faculdades de medicina da corte do Rio de Ja-

2. O sobrenome do autor é incorporado no dia-a-dia para significar o próprio livro. 
neiro e da Bahia, em 1832, e que tinham na Academia de Medicina de Paris seu maior referencial. Os manuais de medicina popular, portanto, foram o retrato das aspirações civilizadoras do período: levar a verdade ao povo. Tais aspirações podem ser observadas logo nos prefácios, quando os autores afirmavam ter adaptado o vocabulário à “inteligência das pessoas comuns”, reconhecendo a necessidade de abolirem termos só utilizados nos tratados médicos. Apresentavamse a partir de uma perspectiva higienista, e revelaram, também, a preocupação da medicina institucionalizada com a prevenção e o controle de doenças endêmicas e epidêmicas que dizimavam a população.

Os manuais escritos no período imperial apontam para um público bastante amplo, cujo interesse se dirigia a temas, ao mesmo tempo, científicos e presentes no seu cotidiano. O Manual do fazendeiro ou Tratado médico sobre as enfermidades dos negros generalizado às necessidades de todas as classes (Imbert, 1839), o Guia médico das mães de família (Imbert, 1843), o Dicionário de medicina doméstica e popular (Langgaard, 1873), o Dicionário de medicina popular (Chernoviz, 1862), o Primeiros socorros ou a medicina e a cirurgia simplificada (Bonjean, 1866), e O médico e o cirurgião da roça (Bonjean, 1857), entre outros, são títulos que se pretendem à iniciação às ciências médicas de seus leitores. Por outro lado, esses manuais, ainda que adquiridos por famílias ricas ou remediadas ou por indivíduos dados à prática informal da medicina - e, por isso, dentro de categorias distintas da maior parte da população do país -, não se restringiram a esse círculo fechado. Certamente, faziam-se conhecidos nas conversas informais e nas trocas de receitas no ambiente doméstico, para a recuperação de parentes, vizinhos ou escravos doentes. Além disso, prestariam muitos serviços ao grande número de indivíduos leigos que sobreviveram à custa de um conhecimento médico informal.

Para melhor situar os manuais de medicina popular em seu tempo, há que se conhecer a interação entre essas obras e seu público consumidor. Dessa maneira, ampliamos o panorama da medicina, no Brasil imperial, que não se limitou apenas ao estereótipo de, por um lado, uma medicina oficial, praticada unicamente por médicos diplomados, e, por outro, uma medicina descredenciada pela ciência acadêmica do século XIX, e praticada, em vários graus de informalidade, pelos escravos ou por indivíduos pobres que se valiam de seus diferentes saberes para sobreviverem. Entre o estetoscópio e a garrafada, havia um terreno bastante extenso ocupado por diversos outros elementos, dentre os quais, os manuais. E não só manuais; os almanaques (Meyer, 2001; Park, 1999) e os periódicos médicos (Ferreira, 1996) tiveram um importante papel na divulgação da medicina científica no Império.

Os colégios dos jesuítas, na colônia - que se continuaram no Império com os franciscanos -, com seus hospitais e boticas de onde tiravam os remédios 
(Holanda, 1960), serviram como conhecidos centros médicos. Os práticos informais, como boticários, barbeiros-cirurgiões, sangradores, parteiras e curandeiros, teriam o direito (e o dever) de legalizar suas atividades. Este processo de oficialização constava de um pedido da pessoa diretamente interessada, e alguns outros passos para que se passasse a Carta ou a Licença. Estas indicavam o alcance e o limite de sua atividade, e os instrumentos que deveriam utilizar (por exemplo, os curandeiros poderiam tratar com plantas medicinais onde não houvesse médicos, e caso houvesse algum, deveriam estes opinar primeiro).

Entretanto, a imensa maioria desses práticos, também conhecidos pelos nomes de curiosos, anatômicos, algebristas e entendidos (Holanda, 1960), entre outros, pouco interesse teria em tornar oficial sua atividade, por várias razões de ordem sociocultural (Pimenta, 1998). Inicialmente, tratava-se de trabalho manual, que, como se pode perceber através de toda a documentação e bibliografia que aborda os períodos colonial e imperial, era atividade de baixo status social, reservada para escravos, libertos, pobres livres e mulheres. Os barbeiros-sangradores, os chaveiros (Freyre, 1946), que zelavam pelas chaves das dependências da fazenda, mas que também eram dentistas e aplicadores de bichas e ventosas, as parteiras e os curandeiros freqüentavam ambientes muito distantes da clientela dos boticários, cirurgiões e médicos - que também conservavam entre si uma hierarquia, baseada na proximidade ou distância do trabalho manual (Figueiredo, 2002). Assim, grande parte do público que se tratava com os práticos não oficializados, por sua origem social, também não tinha qualquer preocupação ou possibilidade de exigir deles um conhecimento oficializado. A magia e religiosidade que caracterizavam muitas daquelas práticas, por outro lado, as teriam incompatibilizado com as atividades de cura credenciadas pelas autoridades. No Rio de Janeiro, as práticas populares de cura, que aconteciam em todos os bairros, tinham o tempero das feitiçarias de origem africana. Parte das nações africanas da corte praticava rituais religiosos curativos (Karash, 2000); uma das funções mais importantes dos feiticeiros era exatamente curar doenças com cataplasmas de ervas, óleos, emplastros e rezas. Os barbeiros, parte da categoria de feiticeiros sangradores, além de sangrar, "deitar bichas” e tratar de cabelos e barbas, praticavam pequenas cirurgias, como arrancar dentes e abrir tumores, deixando as maiores, como amputações e tratamento de grandes feridas, a cargo dos diversos cirurgiões. A sangria poderia ser realizada pelos barbeiros-feiticeiros ao sol (procedimento, por seus princípios, muito diferenciado da sangria prescrita pela medicina acadêmica), e consistia em escarificar a pele com uma pedra, e sobre essa área colocar um chifre de ovelha com a extremidade maior em contato com a pele, e chupar na outra extremidade (Karash, 2000). Por conta desse caráter mágico e religioso do ofício, a clientela poderia ser, em determinadas situações, um pouco diferente daquela dos médicos e dos cirurgiões licenciados, que ignoraram ou 
desqualificaram essas práticas. Os critérios de escolha entre a medicina dos médicos e a dos curandeiros estariam muito mais ligados à credibilidade e à confiança (Figueiredo, 2002) do que à legalidade.

Os cirurgiões cumpriram o papel de médicos durante os longos anos coloniais e mantiveram uma larga tradição, ainda, ao longo do século XIX, no Brasil. Em 1808, foram criadas, na Bahia e na corte, escolas que visavam, principalmente, a um conhecimento mais formal de anatomia, fisiologia e medicina para os cirurgiões. Em 1813, foram criadas as Academias Médico-Cirúrgicas, que formariam cirurgiões no período de cinco a sete anos, e em 1848, quando já existiam as duas faculdades de medicina, um decreto garantia a esses cirurgiões (aprovados e formados nas Academias) o direito de exercer medicina. Assim, foise produzindo uma nítida e definitiva cisão dentro da vasta categoria dos curadores, cujas inúmeras atribuições variaram, desde feiticeiros sangradores e barbeiros-cirurgiões licenciados a cirurgiões formados. A Sociedade Médica do Rio de Janeiro, em 1829, já admitiria em seus quadros, médicos, cirurgiões, naturalistas e boticários (Ferreira, 1996).

As parteiras parecem ter sido a categoria que mais se manteve refratária a licenças, o que, segundo Maria Renilda Barreto, se deveu ao inegável prestígio com sua clientela que com elas compartilhava crenças e valores (Barreto, 2000). As escravas sempre teriam sido atendidas, durante o parto, por negras velhas que dominavam a prática deste trabalho. No caso das escravas, o parto tinha características de um ritual religioso (Karash, 2000). Distante desse universo, e tentando transformá-lo, Madame Durocher, parteira formada pela Faculdade de Medicina, e que pertenceu à seção de partos da Academia Imperial de Medicina, compôs uma imagem negativa da parteira ilegal - suja, ignorante, perversa, alcoviteira, alcoólatra, supersticiosa, além de "destras na arte do aborto, do infanticídio e da feitiçaria” (Barreto, 2000) - compartilhada por Gilberto Freyre, que foi informado por um médico que,

... quando elas saíam a serviço, era debaixo de uns mantos ou xales compridos, como umas cocas; muitas "levando debaixo das mantilhas cartas de alcoviteiras, feitiços e puçangas; algumas conduzindo também, "a abandonar nas ruas e recantos, os produtos das práticas ilícitas e criminosas a que essa profissão se presta e a que sem escrúpulos se entregavam”. (Freyre, 1946)

Os médicos que iam chegando, bem devagar, aos interiores, se ignoravam ou desrespeitavam os fundamentos religiosos e mágicos das práticas ditas populares, não deveriam possuir, obrigatoriamente, perfil tão soberbo como o sugerido por Gilberto Freyre. Este autor apresenta as "gerações mais novas de filhos de senhores de engenho, os rapazes educados na Europa, na Bahia, em São Paulo, em Olinda, no Rio de Janeiro” como desertores dos conceitos patriarcais de mo- 
ral, justiça e política que não se conciliariam com seus gostos "afrancesados, urbanizados e policiados”, e assim, também atribui ao jovem médico o papel de "desprestigiador da medicina caseira, que era um dos aspectos mais sedutores da autoridade como que matriarcal de sua mãe ou de sua avó, senhora de engenho" (Freyre, 1951). Afinal, a medicina também entrou nas casas-grandes e sobrados sob a forma de livros, revistas médicas e almanaques. No final da segunda década do século XIX, com o fim da censura imposta aos livros pela Coroa portuguesa, vão aumentando progressiva e substancialmente o número de livrarias e de impressoras, no Brasil (em 1808 havia apenas uma tipografia; em 1829, sete; e em 1850, trinta), e o comércio de obras de medicina para leigos conquistaria um mercado considerável (Hallewell, 1985). Tais livros ensinavam os senhores a tratar as doenças dos escravos para aumentar o seu capital, "tentando juntar a filantropia leiga dos reformistas europeus aos interesses bem entendidos dos escravocratas", e tentavam responder aos problemas graves de saúde pública, que atingiam, também, as classes mais altas do Império, como a mortalidade ligada ao parto (Alencastro, 1997).

Os manuais de medicina popular escritos durante o Império não eram só adjuvantes do conhecimento acadêmico, mas ferramentas essenciais no tratamento dos doentes, principalmente no interior do Brasil. Assim, cirurgiões, curandeiros e autodidatas vão ser encontrados com manuais nas mãos, mas fazem-se notar, especialmente, os boticários e os fazendeiros.

As boticas foram o principal ponto de encontro e de conversas das pequenas vilas, e seus donos e empregados cumpriam, desde os tempos coloniais, o papel de médicos na região, bastante informados pelos formulários médicos (Marques, 1999).

Os latifúndios obrigavam os fazendeiros a cuidar de tudo e de todos os que lhe pertencessem - aí se incluem os escravos. No campo das doenças, a abordagem pessoal (e, muitas vezes, delicada) pela qual os senhores e as sinhás matriarcas cuidavam e medicavam seus escravos fazia com que os doentes fossem sempre muito reconhecidos, segundo a memorialista Maria Paes de Barros (Barros, 1998).

Os manuais, que muito ajudaram a estes senhores e senhoras no tratamento dos escravos doentes, ilustraram-nos sobre hábitos higiênicos e indicavam fórmulas domésticas para prevenção e tratamento de outros tantos males. Sem a pretensão de generalizar os costumes médicos da sociedade do interior do Brasil Império, três referências que se seguem ajudam um pouco a elucidar a dimensão da rede de serviços médicos que a elite fundiária estabeleceu no interior do país, ora como curadores instruídos pelos manuais de medicina popular, ora como clientes, na busca de outras práticas médicas populares do Império. Por outro lado, a consulta a alguns livros e ao manual do Chernoviz mostra uma das 
formas pelas quais a medicina acadêmica - ainda que exercida pelos fazendeiros - estava se disseminando e convivendo com as demais práticas médicas populares, já velhas conhecidas dos próprios senhores, dos escravos e dos colonos pobres.

Nas reminiscências da infância e da juventude passadas nos meados do século XIX, Anna Ribeiro de Góes Bittencourt (Bittencourt, 1992) e Maria Paes de Barros (Barros, 1998), filhas de famílias latifundiárias (respectivamente, do Recôncavo Baiano e de São Paulo), é significativa a presença do Chernoviz. Outro exemplo, retratado por Lycurgo Santos Filho, sobre farta documentação cedida por uma família baiana, os Canguçu, também reproduziu a vida diária de gerações de criadores de gado (Santos Filho, 1956), que exercitavam a medicina através de livros, na Fazenda Brejo do Campo Seco.

Na região de Piracicaba, onde a família Paes de Barros possuía cafezais, quem participava da administração da fazenda e tomava as decisões de ordem médica era também a própria sinhá, a mãe da memorialista Maria Paes de Barros, ajudada por uma escrava que servia de enfermeira. "Todos os dias vinha a preta enfermeira trazer notícias e pedir conselhos [à senhora] sobre os doentes.” A senhora visitava

... a enfermaria das pretas e a dos pretos. Dotada de singular tino médico, ia aplicando cautelosamente os medicamentos, usando somente processos brandos cataplasmas, fomentações e chás por ela mesma preparados. Somente nos casos mais graves, para os doentes de pneumonia, é que aplicava cáusticos feitos com cantáridas esmagadas; depois, com uma tesoura fina, cortava com cuidado a pele da empola que se formava. Sobre a ferida viva, colocava então uma folha de bananeira untada de óleo, previamente aquecida para adquirir flexibilidade. E assim toda dedicação e bondade, só depois de muitas recomendações sobre o tratamento e dieta de um doente é que passava a outro (...) Estes a olhavam cheios de confiança, seguindo-lhe os conselhos... (...) A bem sortida farmácia da mamãe servia principalmente para acudir os escravos nas suas enfermidades e acidentes, bem como aos colonos ainda mal aclimatados. (Barros, 1998)

Sua preciosa farmácia se compunha de uma grande caixa de botica com vasto sortimento de drogas, como sal amargo, linhaça, vermífugos, arnica, purgantes, xarope de agrião, preparados de limão com ferro velho para opilação, pomadas e ungüentos, entre diversas outras. Muita gente, inclusive os europeus que trabalhavam em suas terras e que - segundo a autora - ainda estavam passando pelo conhecido fenômeno da aclimatação, era curada de seus vermes e feridas pelos constituintes da farmácia, com o auxílio dos manuais de Chernoviz (Barros, 1998).

A mãe da memorialista Anna Ribeiro de Góes Bittencourt, no Recôncavo Baiano, também exercia sua medicina, e, tal qual sua contemporânea paulista, 
atuava junto a todos os escravos, já que “... no campo, onde residia, o mister de dona de casa era bem pesado”, pois “a mãe de família tinha de desempenhar até o cargo de enfermeira, não só com os escravos do serviço doméstico, mas também com os muito numerosos do trabalho agrícola” (Bittencourt, 1992).

O papel das mulheres no tratamento dos doentes foi observado também por Alain Corbin, ao falar das famílias refinadas francesas. Ele mostrou como as mulheres influenciavam, tanto na reputação do médico da família, quanto na gerência da saúde, formando uma "complexa rede medicinal paralela. (...) Uma farmácia, evidentemente, muito simples, funciona nos castelos; as aristocratas a utilizam. São elas que curam os pobres do lugar” (Corbin, 1991).

Uma associação curiosa de medicina leiga com religião, curandeirismo e manual médico foi ricamente descrita por Anna Bittencourt, nascida em 1843, em Catu, onde viveu com sua família numa fazenda. Além de abastada, Anna foi educada com os clássicos da época, escrevia romances, e recebia em sua casa parentes médicos e advogados, o Monsenhor Silveira (importante figura eclesiástica e da imprensa da Bahia e de Sergipe), e suas afilhadas, além de vários outros amigos e familiares versados em francês e latim. Por outro lado, a família foi bastante peculiar, no que se refere à medicina: simultaneamente, demonstrava respeito e descrédito a esta ciência. Quando criança, um problema na vista atrasou a alfabetização de Anna e a impediu, também, de costurar. Seus pais nem chegaram a recorrer a cuidados médicos, porque "A ciência de Hipócrates não estava em tão grande crédito entre os habitantes de nosso campo e, para desanimar meus pais, havia tristes casos [de doenças oculares] em nossa família...”, mas a paciente tomava remédios, possivelmente receitados pelo Chernoviz de seu pai, “... remédios de sabor péssimo que muito me custava tragar, [além de um] cruel tratamento de cáusticos, então muito usados, que tantas horas de insuportáveis dores me valeram” (Bittencourt, 1992). O avô, Pedro Ribeiro, perdendo também a visão, procurou o médico mais famoso da capital da Bahia, mas este lhe desenganara. Recorreu, então, à ajuda de um negro, irmão do convento de São Francisco, que, após constatar a ineficácia de suas próprias orações, tentou convencer o doente de que a cegueira significava uma proteção divina à sua família (Bittencourt,1992).

O primeiro dono da fazenda Brejo do Campo Seco, estudada por Santos Filho, ainda no século XVIII, tinha por hábito (que não parece ter sido particular a esta família) escrever no seu Livro de Razão ${ }^{3}$ receitas, prescrições, fórmulas e doses de remédios, copiadas de outros livros, para que não fossem esquecidas

3. Livro doméstico onde se anotavam compras e vendas de gado, de escravos, de alimentos.

Rev. Latinoam. Psicopat. Fund., São Paulo, v. 11, n. 4, p. 827-840, dezembro 2008 (Suplemento) 
através da transmissão apenas oral, como o "Remedio pa. curar Gonorrea (huma colher de azeite doce posto com huma gema de ovo imorna [amorna] ao fogo beba em jejum 5 dias e [ilegível] q’ sara da purgação q’ ouver deter...)”. Esse fazendeiro atuava junto à sua família e a seus escravos, mas também nas vizinhanças, fazendo curativos de feridas, receitando "drogas do Reino e raízes da terra" (Santos Filho, 1956) e mezinhas. Um herdeiro da fazenda, já na segunda metade do século XIX - Exupério Canguçu -, era também excelente curador e, para consultas, usava o Chernoviz, que, provavelmente, o ilustrou sobre as diversas técnicas cirúrgicas, receitas e sangrias. A fama dos Canguçu como médicos deve ter se comparado à sua fama de violentos (Peixoto, 1962), ambas extrapolando os limites de sua propriedade (Santos Filho, 1956).

A utilização do Chernoviz, por esses senhores, introduziu uma rotina de prestação de cuidados médicos. Como "todo fazendeiro tornou-se curandeiro nos seus domínios” (Santos Filho, 1956), as famílias de Maria Paes de Barros, de Anna Bittencourt e de Exupério Canguçu, sempre informadas pelo Chernoviz, praticavam uma medicina para os escravos e para seus familiares, extensiva a colonos e a diversas outras pessoas da região. Não ficam muito claras as distinções - evidentemente não seriam poucas - entre os tratamentos dados a uns e a outros, mas esses médicos atuavam em função de uma rede de comunicação que se construiu pela carência de cuidados aos pobres do interior do país.

A bibliografia especializada, a literatura ficcional e algumas das biografias citadas ao longo deste trabalho mostram que, enquanto os médicos eram quase sempre inacessíveis, e manipulavam um saber hermético e estranho aos extratos populares, os curandeiros, por eles denunciados como charlatães, produziram diversas sínteses, aproximando sincreticamente elementos da medicina científica da linguagem compartilhada pelos diferentes grupos subalternos.

A importância dos manuais de Chernoviz para os boticários pode ser avaliada pelo seu respaldo oficial (Araújo, 1962), através dos regulamentos da Junta de Higiene, criada em 1851. Enquanto aguardava-se a criação de uma Farmacopéia Brasileira (só criada em 1929), alguns formulários foram indicados por uma comissão de técnicos da Junta, como imprescindíveis para uma farmácia, e, a partir de então, o Formulário de Chernoviz foi o mais seguido.

\section{Referências}

Alencastro, L. F. Vida privada e ordem privada no Império. In: Novais, F. A. História da Vida Privada no Brasil. São Paulo: Companhia das Letras, 1997. v. 2, p. 67-78. 
Araúso, C. S. Le Docteur Czerniewicz (Chernoviz), ses livres et son infuence sur la pharmacie et la practique médicale au Brésil. In: CracoviA, XVIII Congresso Internacional de História da Medicina,1962.

Barreto, M. R. N. Nascer na Bahia do século XIX. 2000. 138f. Dissertação (Mestrado em História). Faculdade de História, Universidade Federal da Bahia, Salvador.

Barros, M. P. No tempo de dantes. São Paulo: Paz e Terra, 1998.

Bittencourt, A. R. G. Longos serões do campo. Rio de Janeiro: Nova Fronteira, 1992.

Bonjean, L. F. O médico e o cirurgião da roça. Rio de Janeiro: Eduardo e Henrique Laemmert, 1857.

. Primeiros socorros ou a medicina e a cirurgia simplificada. Rio de Janeiro: Eduardo e Henrique Laemmert, 1866.

Chernoviz, P. L. N. Carta de 21 de julho de 1840. In: Herson, B. Cristãos-novos e seus descendentes na medicina brasileira (1500-1850). São Paulo: Edusp, 1996.

. Dicionário de medicina popular. 3. ed. Paris: Casa do Autor, 1862.

. Dicionário de medicina popular. 6. ed. Paris: A. Roger\& F. Chernoviz, 1890.

Corbin, A. Bastidores. In: Arries e Duby. História da vida privada. São Paulo: Companhia das Letras, 1991. v. 4.

FERreira, L. O. O nascimento de uma instituição científica: o periódico médico brasileiro na primeira metade do século XIX. 1996. 214f. Tese (doutorado em História Social). Departamento de História, Faculdade de Filosofia, Ciências e Letras da Universidade São Paulo - USP.

Figueiredo, B. G. A arte de curar: cirurgiões, médicos, boticários e curandeiros no século XIX em Minas Gerais. Rio de Janeiro: Vício de Leitura, 2002.

FonseCA, L. A. Memória histórica da Faculdade de Medicina da Bahia relativa ao ano de 1859. São Paulo: Hucitec/Edusp, 1997.

FreYre, G. Casa-grande \& senzala. Rio de Janeiro: José Olympio, 1946. . Sobrados e mucambos. Rio de Janeiro: José Olympio, 1951.

Guimarães, M. R. C. Civilizando as artes de curar: Chernoviz e os manuais de medicina popular no Império. 2003. 104f. Dissertação (Mestrado em História das Ciências da Saúde). PPGHCS - COC/Fiocruz, Rio de Janeiro.

Hallewell, L. O livro no Brasil (sua história). São Paulo: Edusp, 1985.

Holanda, S. B. A época colonial. São Paulo: Difusão Européia do Livro, 1960.

ImBert, J. B. A. Manual do fazendeiro ou tratado doméstico sobre a enfermidade dos negros generalizado às necessidades de todas as classes. 2. ed. Rio de Janeiro: Tipografia Nacional, 1839. $2 \mathrm{v}$.

Rev. Latinoam. Psicopat. Fund., São Paulo, v. 11, n. 4, p. 827-840, dezembro 2008 (Suplemento) 
. Guia médico das mães de família. Rio de Janeiro: Tipografia Franceza, 1843.

Karash, M. C. A vida dos escravos no Rio de Janeiro (1808-1850). São Paulo: Editora Schwarcz Ltda., 2000.

Langgaard, T. J. H. Dicionário de medicina doméstica e popular. 2. ed. Rio de Janeiro: Eduardo \& Henrique Laemmert, 1873. 3 v.

Marques, V. R. B. Natureza em boiões: medicinas e boticários no Brasil Setecentista. Campinas: Ed. Unicamp, 1999.

Meyer, M. Do almanak aos almanaques. São Paulo: Ateliê Editorial, 2001.

Park, M. B. Histórias e leituras de almanaques no Brasil. Campinas: Mercado das Letras; São Paulo: Associação de Leitura do Brasil/Fapesp, 1999.

Peixoto, A. Sinhazinha. In: Obras completas. Rio de Janeiro: Nova Aguilar, 1962.

Pimenta, T. S. Barbeiros-sangradores e curandeiros no Brasil (1808-1828). História, Ciências, Saúde - Manguinhos, Rio de Janeiro, v. V, n. 2, p. 349-72, jul-out.1998.

Santos Filho, L. Uma comunidade rural no Brasil Antigo. São Paulo: Companhia Editora Nacional, 1956.

. História geral da medicina brasileira. São Paulo: Hucitec/Edusp, 1991.

\section{Resumos}

(Los manuales de medicina popular del Imperio y las enfermedades de los esclavos: el ejemplo de "Chernoviz")

Este trabajo presenta los conocidos manuales de medicina popular de autoría del polonés Pedro Luiz Napoleão Chernoviz (1812-1881) en el contexto médico del Brasil imperial, tanto como elementos de divulgación de la ciencia médica académica como elementos de la propia medicina popular (lega). El carácter académico, pedagógico, civilizador y higienista de estos manuales del Imperio capacitaba personas del interior del país, distantes de los médicos para la práctica de primeros socorros y para la formulación de diversos tipos de medicamentos.

Palabras clave: Chernoviz, medicina popular, Brasil-Império, manuales médicos

(Les manuels de médicine populaire de l'Empire et les maladies des esclaves: l'exemple de "Chernoviz")

Cet étude porte sur les fameux manuels de médecine populaire rédigés par le médecin polonais Pedro Luiz Napoleão Chernoviz (1812-1881) et de leur présence dans le contexte médical de l'Empire du Brésil. Ces manuels étaient à la fois des 
éléments de divulgation de la science médicale académique et des éléments de médicine populaire laïque. Leur caractère académique, pédagogique, civilisateur et hygiéniste enseignaient aux gens de la campagne, qui vivaient loin des médecins, des mesures de premiers secours ainsi que des formules de divers remèdes.

Mots clés: Chernoviz, médecine populaire, Brésil-Empire, manuels médicaux

(Manuals of folk medicine in Brazil's imperial times and diseases of slaves: the example of the Chernoviz Dictionary)

This work presents the well known popular medical handbooks wrote by the polish doctor Pedro Luiz Napoleão Chernoviz (1812-1881) in the imperial Brazil medical context. These handbooks were elements of the academical medical science disclosure and elements of popular (lay) medicine as well. Their academic, pedagogical, civilizer and hygienist role gave to the rural people, faraway from the regular doctors, the understandig of emergence therapies and the formulation of may kinds of medicines.

Key words: Chenoviz, popular medicine, Brazil-Empire, medical handbooks

Versão inicial recebida em junho de 2008 Versão aprovada para publicação em outubro de 2008

\section{Maria Regina Cotrim Guimarães}

Mestre e doutoranda em História das Ciências e da Saúde - COC/FIOCRUZ (Rio de Janeiro, RJ, Brasil); médica do IPEC/FIOCRUZ.

Rua Assis Bueno 46/401 - Botafogo

22280-080 Rio de Janeiro, RJ, Brasil

e-mail: maria.regina@ipec.fiocruz.br

Rev. Latinoam. Psicopat. Fund., São Paulo, v. 11, n. 4, p. 827-840, dezembro 2008 (Suplemento) 